\title{
REVIEW
}

\section{Clinical review: Update on neurally adjusted ventilatory assist - report of a round-table conference}

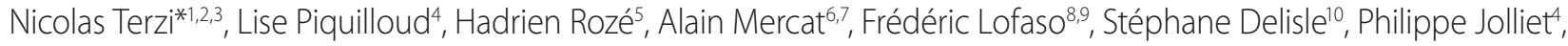 \\ Thierry Sottiaux ${ }^{11}$, Didier Tassaux ${ }^{4}$, Jean Roesler ${ }^{12}$, Alexandre Demoule ${ }^{13}$, Samir Jaber ${ }^{14}$, Jordi Mancebo ${ }^{15}$, Laurent \\ Brochard ${ }^{9,16}$ and Jean-Christophe Marie Richard ${ }^{16,17,18}$ \\ Report from the Geneva Round Table
}

\begin{abstract}
Conventional mechanical ventilators rely on pneumatic pressure and flow sensors and controllers to detect breaths. New modes of mechanical ventilation have been developed to better match the assistance delivered by the ventilator to the patient's needs. Among these modes, neurally adjusted ventilatory assist (NAVA) delivers a pressure that is directly proportional to the integral of the electrical activity of the diaphragm recorded continuously through an esophageal probe. In clinical settings, NAVA has been chiefly compared with pressure-support ventilation, one of the most popular modes used during the weaning phase, which delivers a constant pressure from breath to breath. Comparisons with proportional-assist ventilation, which has numerous similarities, are lacking. Because of the constant level of assistance, pressure-support ventilation reduces the natural variability of the breathing pattern and can be associated with asynchrony and/or overinflation. The ability of NAVA to circumvent these limitations has been addressed in clinical studies and is discussed in this report. Although the underlying concept is fascinating, several important questions regarding the clinical applications of NAVA remain unanswered. Among these questions, determining the optimal NAVA settings according to the patient's ventilatory needs and/or acceptable level of work of breathing is a key issue. In this report, based on an investigator-initiated round table, we review the most recent literature on this topic and discuss the theoretical advantages and disadvantages of NAVA compared with other modes, as well as the risks and limitations of NAVA.
\end{abstract}

\section{Introduction}

Pressure-support ventilation (PSV) is a widely used mode of assisted mechanical ventilation (MV), notably during the weaning phase [1,2]. Although PSV has been proven valuable in several acute clinical conditions $[3,4]$, predefined ventilator settings - for example, airway pressure (Paw) - that remain unchanged from breath to breath are unlikely to provide optimal assistance all of the time.

To improve the match between the patient's needs and the assistance delivered by the ventilator, manufacturers have developed several new modes of MV $[5,6]$. Among these new modes we identified proportional-assist

*Correspondence: terzi-n@chu-caen.fr

${ }^{3}$ CHRU Caen, Service de Réanimation Médicale, Caen F-14000, France

Full list of author information is available at the end of the article ventilation (PAV) and neurally adjusted ventilatory assist (NAVA).

PAV is a mode of support in which the ventilator pressure is proportional to instantaneous flow and volume, and hence to pressure generated by the respiratory muscles [7]. Previous studies have demonstrated that PAV improves the synchrony between patient and ventilator, during several clinical conditions [8-12]. Based on the principles of the equation of motion, software (PAV+; Covidien, Boulder, Colorado, USA) has been developed that automatically adjusts the flow assist and the volume assist so that they always represent constant unloading fractions of the measured values of resistance and elastance loadings of the respiratory system [13-15]. Recent studies demonstrated that PAV+ is a safe and efficient ventilator mode in critically ill intubated patients $[16,17]$. During PAV the ventilator provides support only during the remaining duration of inspiratory effort, 
which can cause limitation when dynamic hyperinflation is present and when the inspiratory trigger is delayed due to intrinsic end-expiratory pressure.

The other support mode is NAVA, which will be discussed in this article. There are several similarities between PAV and NAVA, but this first round-table meeting focused on NAVA. A vast literature also exists concerning PAV, but this topic would require a whole chapter and will not be discussed in this current paper; hopefully PAV will be the topic of a different round table.

The present article is based on an investigator-initiated round-table meeting. The article aims to review the available knowledge on the physiological rationale and feasibility of the recently introduced NAVA MV modality. Throughout the article, we place emphasis on the most recent findings concerning adjustment of the NAVA settings; on the one hand considering specific issues associated with assisted modes of MV, and on the other considering the expectations placed upon NAVA.

NAVA is an assist mode of MV that delivers a pressure proportional to the integral of the electrical activity of the diaphragm (EAdi) [18], and therefore proportional to the neural output of the patient's central respiratory command. The level of pressure delivered is thus determined by the patient's respiratory-center neural output. With NAVA, the ventilator is triggered and cycled-off based on the EAdi value, which directly reflects the activity of the neural respiratory command. The inspiratory airway pressure applied by the ventilator is determined by the following equation:

$$
\text { Paw }=\text { NAVA level } \times \text { EAdi, }
$$

where Paw is the instantaneous airway pressure $\left(\mathrm{cmH}_{2} \mathrm{O}\right)$, EAdi is the instantaneous integral of the diaphragmatic electrical activity signal $(\mu \mathrm{V})$, and the NAVA level $\left(\mathrm{cmH}_{2} \mathrm{O} / \mu \mathrm{V}\right.$ or per arbitrary unit) is a proportionality constant set by the clinician.

In February 2011, several European and Canadian investigators with clinical results about NAVA available in publication or in abstract format organized a roundtable discussion at the Geneva University Hospital to describe and discuss recent advances regarding NAVA. A representative of the company that commercializes the NAVA machine (Maquet Critical Care SA, Sölna, Sweden) was invited to attend the meeting in order to answer only technical questions. Maquet Critical Care SA agreed to sign a disclosure form before the meeting specifying that neither the minutes of the meeting nor the content of the report could be modified and/or used for commercial purposes. The main purpose of this meeting was for all of the investigators and participants to expose their standpoint and questions about NAVA, and to share the main results of their studies. Maquet
Critical Care SA agreed to provide financial support for organizing the meeting, as detailed at the end of the manuscript, but was not responsible for choosing participants and did not take any part in the writing of this report. We here describe the content of the round-table discussion, focusing on a selection of the most recent studies [19-33] (Table 1).

\section{Main problems with conventional ventilation modalities in the ICU}

Assisted modes generally aim at synchronizing the ventilator insufflation to the patient's effort, both to optimize comfort and to minimize the work of breathing. The price to pay for this strategy is a risk of patientventilator asynchrony, which can be defined as a mismatch between the patient's neural output and the ventilator's inspiratory and expiratory times [34-37]. Thille and colleagues reported that one-quarter of patients had high rates of asynchrony during assisted ventilation [34]. Frequent asynchrony is associated with a longer duration of MV [34,38].

Compelling evidence accumulated over the last decade also supports the use of tidal volume $\left(\mathrm{V}_{\mathrm{T}}\right)$ values that are lower than those traditionally used. Lower $\mathrm{V}_{\mathrm{T}}$ values than traditionally used have several main advantages: they diminish the risk of ventilator-induced lung injury [39-41]; they preserve spontaneous breathing by avoiding respiratory alkalosis, thus preventing diaphragmatic disuse atrophy associated with MV [42-48]; they diminish several types of patient-ventilator asynchrony [49]; and they may improve the efficiency of gas exchange [50]. Assisted modes of ventilation that maintain at least part of the patient's spontaneous breathing activity contribute to preventing these pulmonary and muscular complications.

The new challenge in developing ventilation strategies thus consists of minimizing the risk of lung injury, avoiding disuse atrophy of the diaphragm, and improving the match between the patient's needs and the assistance delivered by the ventilator [6]. New ventilation modes have been designed to meet this challenge [5], and NAVA is a pressure-assisted mode in which the pressure delivered by the ventilator is proportional to the electrical activity of the diaphragm recorded continuously through an esophageal probe [18]. NAVA theoretically delivers pressure proportional to the neural output of the patient's central respiratory command. During NAVA, however, reliable positioning of the catheter is mandatory in order to obtain a representative EAdi signal from the diaphragm. Barwing and colleagues have evaluated whether a formula based on the measurement from nose to ear lobe to xiphoid process of the sternum (the NEX distance) modified for the EAdi catheter (NEXmod) is adequate for predicting the accurate position of the esophageal probe [51]. They observed in 18 of 25 patients 


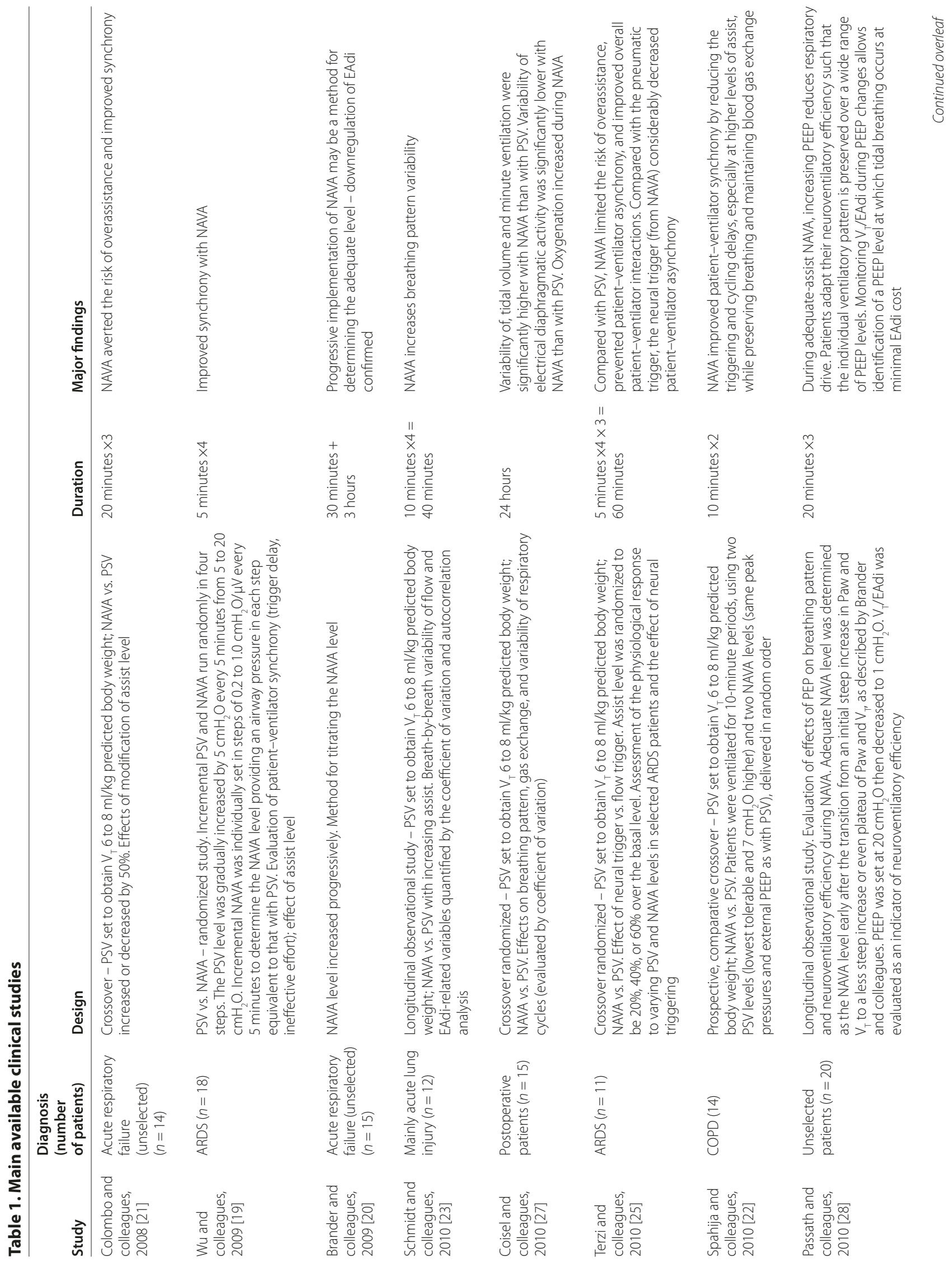


(72\%) that at NEXmod the EAdi signal was suitable for running NAVA. The NAVA mode was possible at the optimal position in four patients - the optimal position being defined by checking three criteria: stable EAdi signals, electrical activity highlighted in central leads of the catheter positioning tool, and an absence of the pwave in the distal lead. The authors thus concluded that positioning the EAdi catheter using NEXmod gives a good approximation in most of the patients.

Moreover, the body position, positive end-expiratory pressure (PEEP) and intra-abdominal pressure are factors known to influence the position of the diaphragm. Barwing and colleagues therefore enrolled 20 patients in order to evaluate the effects of these factors on catheter position [52]. They evaluated six different situations regarding the PEEP, body position and intra-abdominal pressure. Their results demonstrated that these factors may modify the EAdi catheter optimal position, although not compromising a stable signal due to the wide electrode array. One can therefore conclude that the optimal catheter position should be adjusted after major changes in ventilator settings, clinical condition or patient positioning.

\section{Management of patient-ventilator synchrony}

The time lag between the neural inspiratory input and the occurrence of a ventilator breath affects all steps of the respiratory cycle (initiation, insufflation, and cyclingoff for expiration) [53]. Among the different forms of asynchrony, ineffective triggering (also known as wasted effort) is the most common during invasive MV. During noninvasive ventilation (NIV), leaks at the patientventilator interface impair the function of the pneumatic trigger and cycling system [54], thus promoting specific asynchronies (autotriggering and prolonged insufflation) [55].

Ineffective efforts are explained both by patients' characteristics and by ventilator settings. The presence of intrinsic PEEP increases the patient effort required to trigger the ventilator, thereby increasing the likelihood that the patient's inspiratory effort will fail to trigger a ventilator breath $[36,53,56]$. A weak inspiratory effort, which may occur during situations of low respiratory drive such as excessive ventilation, is also a risk factor and is common in patients receiving high assist levels [22] or sedation [38]. An excessive level of pressure support is also associated with prolonged insufflation, thus promoting hyperinflation and intrinsic PEEP. Reduction of ineffective efforts is often possible through a careful optimization of ventilator settings, at least in short-term studies. Reducing $\mathrm{V}_{\mathrm{T}}$ during PSV can improve most factors contributing to ineffective efforts [49]. Thille and colleagues showed that wasted efforts could be decreased without increasing the patient's work of 
breathing, with the main goal of decreasing the pressuresupport level to obtain $\mathrm{V}_{\mathrm{T}}$ values of about $6 \mathrm{ml} / \mathrm{kg}$ predicted body weight [49]. Because high pressuresupport levels are associated with prolonged insufflation beyond the end of the patient's neural inspiratory time, another useful means of decreasing wasted efforts consists of adjusting the inspiratory time by increasing the flow threshold of the cycling criterion $[49,57]$.

\section{Neurally adjusted ventilatory assist and asynchrony}

NAVA involves the transesophageal recording of diaphragmatic electrical activity using specifically designed technology to minimize measurement errors. The EAdi signal reliably monitors and controls the ventilatory assist [58]. During NAVA, the EAdi triggers the assist when the patient initiates an inspiratory effort - even during expiration with intrinsic PEEP - and a decrease in EAdi terminates the assist. NAVA does not therefore depend on measurements of airway pressure or flow and keeps the assist synchronous with the inspiratory efforts (independent of the presence of leaks or intrinsic PEEP) $[19,21,22,25,29,59]$. NAVA thus has two important features: the delivered pressure is, in theory, synchronous with the diaphragmatic activity, and the $\mathrm{V}_{\mathrm{T}}$ is completely controlled by the output of the patient's respiratory control center [18].

A frequent form of minor patient-ventilator asynchrony is a long inspiratory trigger delay (time lag between the onset of neural inspiration, then the detection of a breath initiated by the patient and, finally, the onset of ventilator pressurization). Several factors may increase the inspiratory trigger delay during PSV, including the presence of intrinsic PEEP and suboptimal ventilator performance [60]. The cycling-off delay is the time difference between the end of the neural inspiratory ramp and the end of ventilator pressurization. Piquilloud and colleagues compared these delays and their consequences between NAVA and PSV in a group of 22 patients intubated for acute respiratory failure. The inspiratory trigger delay, the excess inspiratory time, and the frequency of patient-ventilator asynchrony were compared between the two modes [26]. Compared with PSV, NAVA substantially improved patient-ventilator synchrony by reducing the inspiratory trigger delay and the total number of asynchrony events, and by improving expiratory cycling-off.

Increasing the level of ventilatory assist with standard modes may expose the patient to potentially dangerous levels of volume and pressure, and to uncoupling between the patient's neural output and ventilator assistance. In contrast to PSV, there is good evidence that NAVA offers protection against excessive Paw and $V_{T}$ values because there is a downregulation of EAdi in response to increasing assistance levels: the net result is a decrease in the amount of assistance provided [20,21,61-63]. The absence of a $V_{T}$ increase with increasing NAVA levels suggests that the Hering-Breuer reflex is operative [64], stopping the output from the respiratory control center at the same $\mathrm{V}_{\mathrm{T}}$ level, irrespective of the NAVA level. Unloading of the respiratory muscles is always partial, as some level of spontaneous activity is maintained, and patientventilator synchrony is improved.

Several studies have evaluated the impact of increasing PSV levels versus NAVA levels using similar methods of setting the ventilator [20-22,25]. Inspiratory pressure support was titrated in order to obtain 6 to $8 \mathrm{ml} / \mathrm{kg}$ predicted body weight during active inspiration. During PSV, the ventilator function 'NAVA Preview' estimates the NAVA level that would achieve the same peak inspiratory pressure. All studies performed in the ICU consistently showed that NAVA, in contrast to PSV, averted the risk of overassistance when the assist level was increased gradually. NAVA also improved patientventilator synchrony, in contrast to PSV, regardless of the underlying diagnosis. Very high levels of NAVA, however, might result in unstable periodic breathing patterns with delivery of high tidal volume followed by periods of apnea and signs of discomfort [65]. To separate the effects of neural triggering and those of proportional assistance, Terzi and colleagues studied a selected population of patients recovering from acute respiratory distress syndrome, using NAVA with two inspiratory triggers: the EAdi signal and the inspiratory flow threshold used previously for PSV [25] (Figure 1a,b). Not only proportional assistance but also neural triggering improved patient-ventilator synchrony in these patients during the weaning process.

All of the available studies of NAVA in ICU patients have limitations regarding the clinical applicability of the results. Except for two studies $[19,25]$, the patient population was heterogeneous in terms of the cause of respiratory failure. The evaluation time was relatively short in eight studies, but not for two studies [24,27].

\section{Matching alveolar ventilation to metabolic demand: role for the neural controller - variability} Interestingly, and for reasons that are not yet fully understood, NAVA compared with PSV seemed to improve the partial pressure of oxygen in arterial blood in some studies independent of changes in the partial pressure of carbon dioxide in arterial blood $\left(\mathrm{PaCO}_{2}\right)$ $[25,27]$. One hypothesis is that the continuous spontaneous inspiratory activity during NAVA improves the matching between ventilation and perfusion. Earlier studies had established that partial ventilatory support allowing some degree of spontaneous breathing activity using modes of ventilation other than NAVA improved the ventilation/perfusion relationship compared with 
(a)
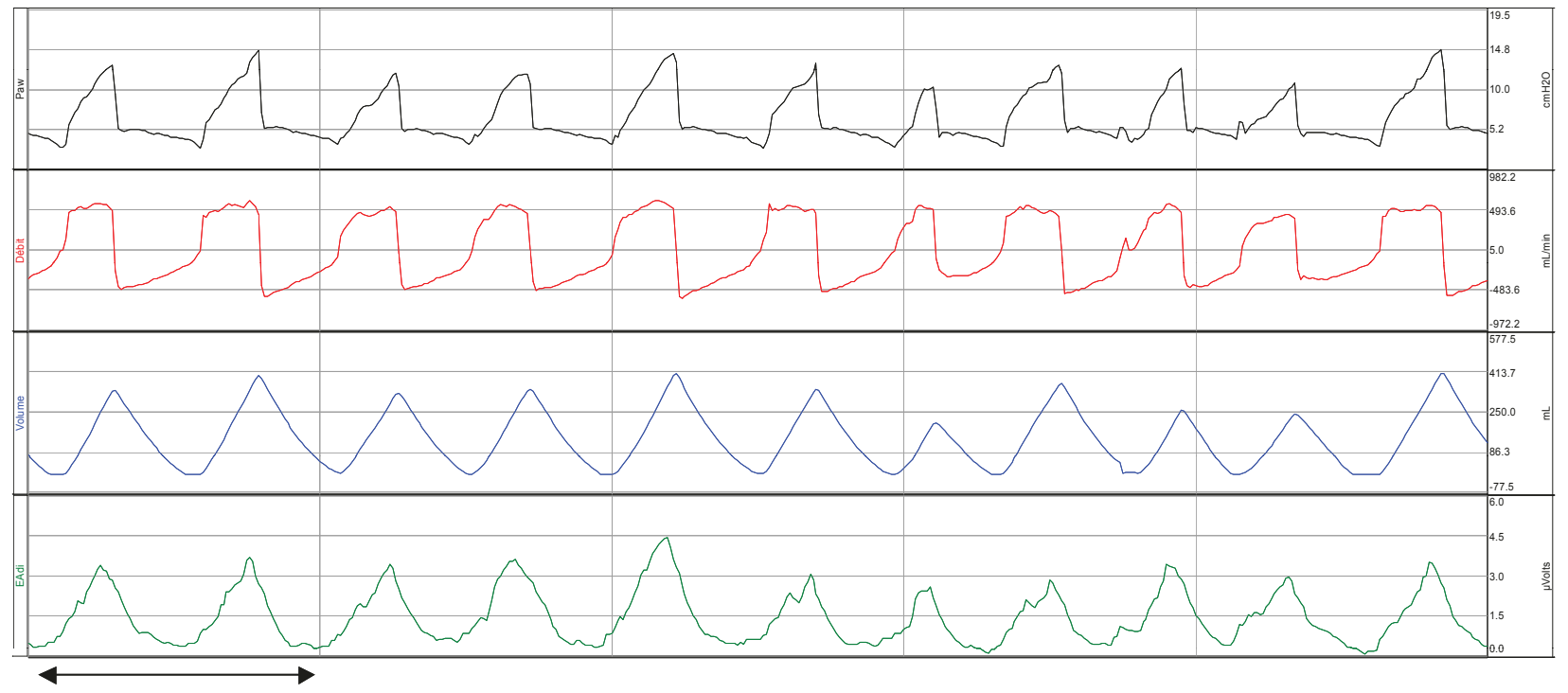

$4 \mathrm{sec}$

(b)

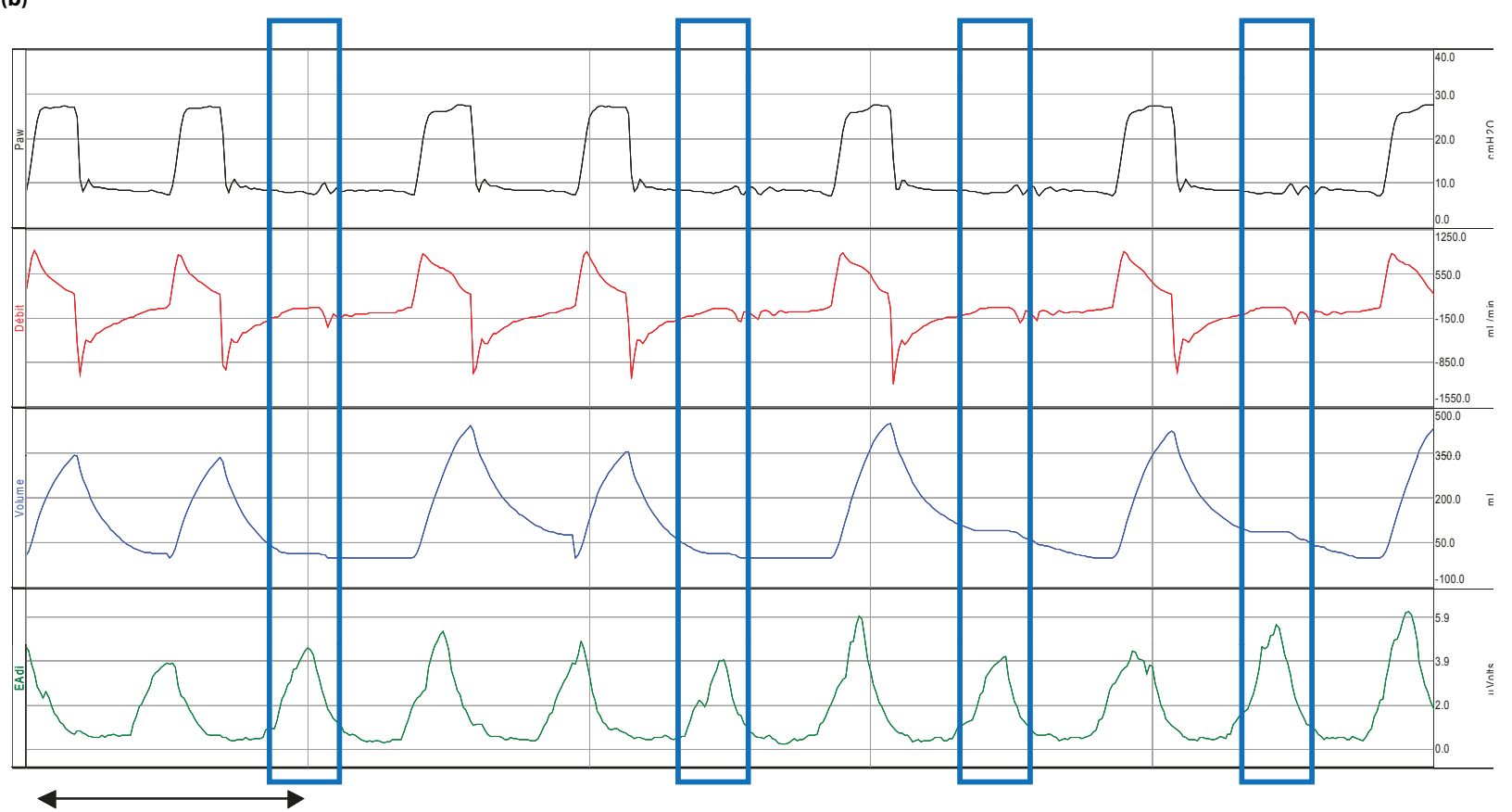

$4 \mathrm{sec}$

Figure 1. Example of recording during neurally adjusted ventilatory assist and pressure-support ventilation. (a) Neurally adjusted ventilatory assist using the neural trigger: no asynchrony was observed. (b) Pressure-support ventilation: wasted efforts are underscored. Each wasted effort is identified by a blue rectangle.

fully controlled MV [66]. In addition, NAVA allows a more natural breathing pattern characterized by greater variability, which may also contribute to improve gas exchange [67] (see below).
According to the principle of homeostasis, the closed loop that regulates $\mathrm{PaCO}_{2}$ comprises: sensors (or detectors), which are chemoreceptors; a controller (or comparator), which is the central respiratory command; and 
effectors, which are the respiratory muscles. Each component controls the next component in the loop, and the effectors change their activity (that is, adapt) to keep the $\mathrm{PaCO}_{2}$ value relatively constant. In other words, EAdi and therefore the breathing pattern must adapt to a variety of conditions to maintain $\mathrm{PaCO}_{2}$ within the normal range. Another regulatory mechanism is optimization of the work of breathing. For example, the rate and/or the depth of breathing can be adjusted to minimize the energy expenditure at a given respiratory effort and/or to minimize the stretch on the lungs.

Any strategy based on automated feedback control of ventilatory support should ideally require neural information on the lung volume, rate of lung volume change, and transpulmonary pressure, which are provided by mechanoreceptors in the lungs and chest wall. Finally, the variability and complexity of the breathing pattern are influenced by several factors, including the load-capacity relationship of the respiratory system [68-70], vagal afferent traffic to the brain [71], and the activity of the central pattern generators [72].

Ventilatory activity is nonlinear in nature and exhibits chaos-like mathematical complexity [72,73]. Variability is a mathematically complex notion, often expressed using the coefficient of variation, which is the ratio of the standard deviation over the mean. However, the complexity of flow and EAdi variability can also be described using noise titration, the largest Lyapunov exponent, Kolmogorov-Sinai entropy, and three-dimensional phase portraits [74,75]. Schmidt and colleagues used these methods to compare respiratory variability and complexity during PSV and NAVA [23]. Compared with PSV, NAVA increased breathing pattern variability and flow complexity without changing EAdi complexity. Accordingly, when the NAVA level was increased from zero to a high level in healthy individuals, they adapted their inspiratory activity to the NAVA level in order to control $\mathrm{V}_{\mathrm{T}}$ and to regulate $\mathrm{PaCO}_{2}$ over a broad range of NAVA settings [63]. In contrast, during high-level PSV, $\mathrm{V}_{\mathrm{T}}$ became almost entirely determined by the ventilator and hypocapnia developed as previously shown in healthy subjects [76,77]. These differences between NAVA and PSV establish that with NAVA, even at a high level of assistance, $\mathrm{V}_{\mathrm{T}}$ is not imposed by the ventilator but remains under the control of the patient's central respiratory command. NAVA therefore decreases the risk of overassistance. The extent to which the preserved variability associated with NAVA is beneficial remains to be established. Whether variability restoration could be used to adapt NAVA settings also warrants further studies, as well as the development of specific tools for assessing variability at the bedside.

Patients with respiratory failure probably adjust their breathing activity to achieve the best compromise between the muscular effort needed to breathe and the sensory cost of tolerating elevated $\mathrm{PaCO}_{2}$ levels. NAVA acts as an additional external cost-free muscle controlled by the central respiratory command. NAVA therefore does not seem to alter the closed loop that controls the $\mathrm{PaCO}_{2}$ and respiratory pattern optimization. Accordingly, when introducing NAVA in patients with respiratory failure, progressively increasing the NAVA level allows the $\mathrm{PaCO}_{2}$ (that is, $\mathrm{V}_{\mathrm{T}}$ ) to improve to the optimal value. Further NAVA level increases then lead to respiratory effort adjustments aimed at maintaining this optimal $\mathrm{PaCO}_{2}$ value, but do not change $\mathrm{V}_{\mathrm{T}}[20]$.

Moreover, Karagiannidis and colleagues intended recently to evaluate the physiological effect of extracorporeal membrane oxygenation on the pattern of breathing in patients with severe lung failure treated with NAVA [78]. They demonstrated that a downregulation of extracorporeal exchange gas transfer caused an immediate upregulation of ventilation. Eucapnia under NAVA was preserved because the patients adjusted their minute ventilation to their needs. These interesting data highlighted once again that the ventilatory adaptation to maintain normocapnia remains under NAVA.

\section{How can the optimal NAVA level be determined?}

Determining the optimal NAVA level remains challenging, and several methods have been suggested. Contrary to PSV and as already described, NAVA generates $V_{T}$ levels that can remain constant independent of the assist level once the patient's ventilation needs appear to be satisfied [20]. Consequently, NAVA settings cannot be adjusted based solely on $\mathrm{V}_{\mathrm{T}}$ (and/or the corresponding $\mathrm{PaCO}_{2}$ target).

Brander and colleagues tried to find the best NAVA level using breathing pattern analysis during a titration procedure [20]. Titration consisted of starting at a minimal assist level of around $3 \mathrm{cmH}_{2} \mathrm{O}$ and then increasing the NAVA level every 3 minutes in steps of $1 \mathrm{cmH}_{2} \mathrm{O}$ per arbitrary unit (the amount of microvolts recorded from the EAdi signal). The response in terms of $\mathrm{V}_{\mathrm{T}}$ and Paw was biphasic. During the first phase, $\mathrm{V}_{\mathrm{T}}$ and Paw increased while the esophageal pressure-time product (that is, inspiratory muscle effort) and EAdi decreased. Further increases in the NAVA level (second phase) did not significantly change Paw or $\mathrm{V}_{\mathrm{T}}$ but continued to decrease the esophageal pressure-time product and EAdi. The first phase may thus indicate an insufficient NAVA level to supplement the patient's weak breathing effort, while the beginning of the second phase may correspond to the minimal assist level that satisfies the patient's respiratory demand. The optimal (or adequate) NAVA level may thus be indicated by the inflection point of the airway pressure trend graph during a stepwise increase in the NAVA level (Figure 2). In this 
study the patients were ventilated with these settings for 3 hours without experiencing adverse hemodynamic or respiratory events [20]. Interestingly, the optimal NAVA level occurred at about $75 \%$ of the highest EAdi obtained with the minimal NAVA level and PEEP [20].

As suggested, titration of the NAVA level may be performed by systematically increasing the NAVA level to determine the optimal setting with regard to unloading patient's respiratory muscles $[20,61,79]$. During a recent observational study, transferring patients to NAVA was uneventful and the NAVA level contributed to adjustments of the preset NAVA level [80]. Interpretation of several interacting physiological parameters might be difficult in cases in which there is no marked decrease in EAdi during NAVA titration [80]. An automated approach enabled faster identification of the best NAVA level with a good accuracy [81].

Instead of stepwise titration, Rozé and colleagues tried to find the best NAVA level using an EAdi target of $60 \%$ of the highest EAdi value recorded during spontaneous breathing [24]. This measurement was reassessed daily using a spontaneous breathing trial with a pressuresupport level of $7 \mathrm{cmH}_{2} \mathrm{O}$ and no PEEP. This method proved feasible and well tolerated until extubation (Figure 3). The $60 \%$ of the highest EAdi value threshold was based on a muscular rehabilitation protocol developed using data on diaphragmatic electromyogram activation during exercise [82]. Whether this approach is also optimal during assisted ventilation needs further evaluation. It is worth noting that EAdi measured during the daily spontaneous breathing trial increased steadily over time in all patients until successful extubation [24]. This improvement probably originated in multiple factors, including discontinuation of sedative agents and gradual restoration of the functional electrophysiologic activity of the diaphragm. Monitoring diaphragmatic activity may be of clinical interest and could be achieved using the NAVA electrode.

Using EAdi analysis to titrate NAVA is an interesting approach that could potentially be easier to use than the breathing pattern analysis method of Brander and colleagues $\left(\mathrm{V}_{\mathrm{T}}\right.$ change during titration) [20]. The EAdi target of $60 \%$ of the highest EAdi value with $7 \mathrm{cmH}_{2} \mathrm{O}$ of PSV proposed by Rozé and colleagues should be used cautiously [24], as Brander and colleagues found that the EAdi at the optimal NAVA level was equal to $75 \%$ of the highest EAdi value recorded with minimal NAVA (inspiratory Paw above PEEP $=3 \mathrm{cmH}_{2} \mathrm{O}$ ) [20]. Further studies are clearly needed to better determine the optimal EAdi target.

\section{Noninvasive ventilation, sleep and NAVA}

NIV is a specific clinical situation during which the occurrence of leaks may greatly affect patient-ventilator

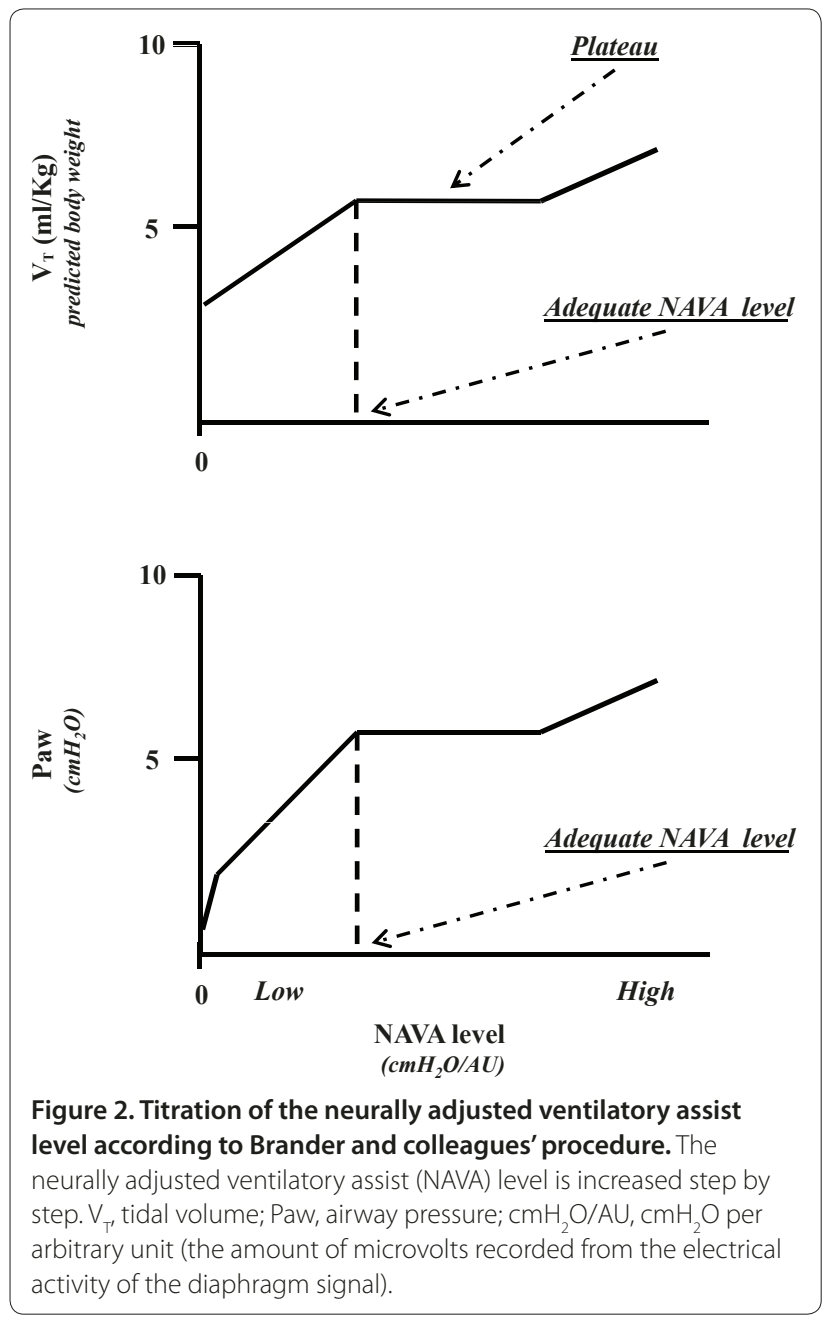

interactions, thereby complicating the determination of optimal ventilator settings. In a study by Vignaux and colleagues, more than $40 \%$ of patients experienced various types of asynchrony during conventional NIV and the asynchrony rate correlated with the level of leakage [83]. With NAVA, assistance is delivered based on neural triggering, which is not affected by leakage. NAVA may thus, in theory, diminish asynchrony events, thereby improving the tolerance of NIV. New software for NIV has been developed using NAVA technology. With this specifically designed algorithm, NIV assistance is triggered and cycled-off by the neural diaphragmatic activity, which would be expected to improve patientventilator synchrony during NIV. This hypothesis has not yet been fully investigated.

A study of NIV-PSV with a helmet interface in healthy volunteers compared asynchrony with a neural trigger and a conventional pneumatic trigger [59]. Increasing PSV levels and respiratory rates applied with neural triggering and cycling-off produced significantly less impairment of synchrony, trigger effort, and breathing 


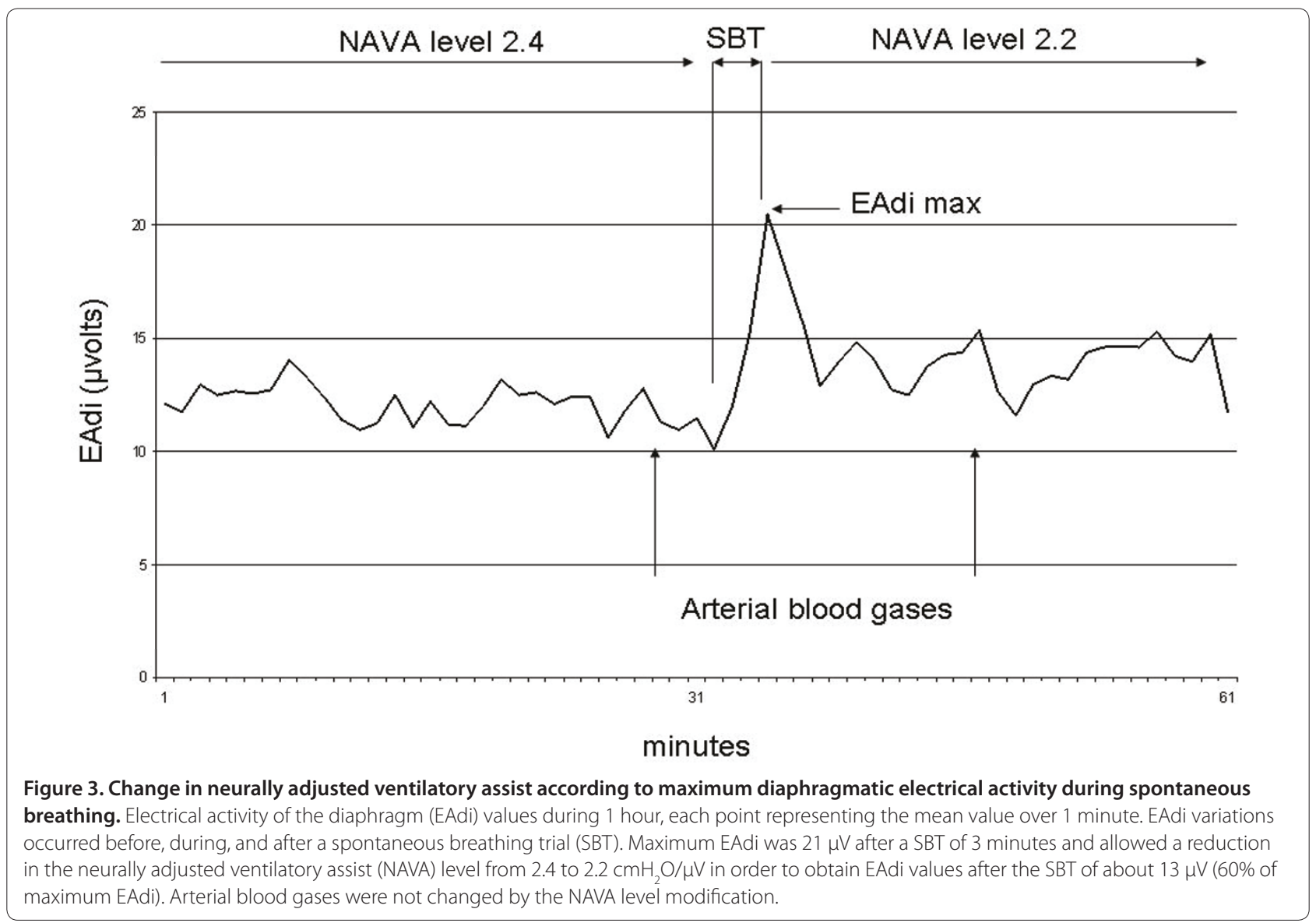

comfort, compared with conventional pneumatic triggering and cycling-off.

Cammarotta and colleagues recently compared NAVA and NIV-PSV delivered through a helmet interface in postextubation hypoxemic patients [32]. Ten patients underwent three 20-minute trials of helmet NIV in PSV, NAVA, and PSV again. The authors demonstrated that there was less asynchrony during NAVA than during PSV and no difference in gas exchange, although there were more leaks during NAVA. Moreover it is important to underline that the PSV mode chosen was specifically dedicated to NIV, whereas the NAVA mode dedicated to NIV that is now currently available did not exist at the time of this study.

Recent data obtained in low-birth-weight infants indicate that NAVA can maintain synchrony - both in terms of timing and proportionality - even after extubation in patients with an excessively leaky interface under NIV (all infants in this study were ventilated using a single nasal prong) [29].

Another consideration for NIV that deserves attention in the near future is the impact on swallowing, phonation, and sleep quality, most notably when NIV is used for several days. Improvements in swallowing performance have been reported in neuromuscular patients receiving MV compared with spontaneous breathing $[84,85]$. The close relationship between the muscles involved in swallowing and those contributing to inspiration was evidenced by Orlikowski and colleagues using an original method of tongue-strength measurement. The significant tongue weakness observed in 16 weak patients with Guillain-Barré syndrome correlated with the alterations in respiratory parameters [86]. Additional physiological studies are required to document the potential benefits of NAVA on swallowing-breathing interactions during NIV.

Sleep quality during NIV has been shown to be a predictor of success or failure [87]. Sleep quality can also be improved compared with standard NIV settings by careful physiological titration of the ventilator settings [88]. Patient-ventilator asynchrony can cause sleep disruption. Bosma and colleagues demonstrated that PAV, a mode of partial ventilatory support in which the ventilator applies pressure in proportion to the inspiratory load, was more effective than PSV in matching the ventilatory requirements to the level of ventilator assistance, thereby resulting in fewer patient-ventilator asynchronies and better quality of sleep [11]. Delisle and colleagues recently obtained sleep recordings during a 
crossover study comparing NAVA and PSV in 14 mechanically ventilated patients [89]. Each condition was studied for 4 hours, and recordings were obtained over 19 consecutive hours in all. Patient-ventilator asynchrony varied significantly across sleep stages, and no asynchrony occurred with NAVA. Overassistance occurred only with PSV, which probably explained the improvements in physiological indices of sleep quality observed with NAVA.

\section{Neurally adjusted ventilatory assist in children and infants}

MV in children and in low-birth-weight infants is more difficult to apply than in adults and has several speciicities. First infants take a very small tidal volume, have a rapid respiratory rate, have a limited chest wall musculature, and have variable and fluctuating lung compliance. Second, most neonatal units use uncuffed tracheal tubes for fears of pressure necrosis and air leak is always present, making reliable measurements and triggering problematic. Third, ventilators that are efficient in adults are not systematically efficient in children and infants, mainly because the inspiratory triggers are not sufficiently sensitive for early detection of infants'/children's inspiratory effort [90].

Whether or not the respiratory drive of the preterm infant is suitable to control MV is unknown. Beck and colleagues first evaluated patient-ventilator interaction with NAVA in seven very-low-birth-weight infants [29]. As suggested by previous animal studies [91], they demonstrated that NAVA could be implemented for a short-term period, both invasively and noninvasively, in infants with body weight as low as $640 \mathrm{~g}$ up to 3 years old. During invasive ventilation with NAVA, EAdi and ventilator pressure were correlated and patient-ventilator synchrony was improved compared with the other mode. Moreover, this synchrony persisted after extubation while ventilating the patient with an excessively leaky interface. After this first physiological demonstration, Bengtsson and Edberg demonstrated the clinical feasibility and safety with use of NAVA in pediatric patients [30]. Similarly, Breatnach and colleagues compared NAVA (with a neural trigger) and PSV (with a pneumatic trigger) in 16 ventilated infants [31]. This prospective crossover comparison demonstrated that ventilation with NAVA improved patient-ventilator synchrony.

Furthermore, Alander and colleagues recently compared NAVA with pressure-controlled ventilation for newborns and with pressure-regulated controlled ventilation for children older than 3 months (with conventional trigger modes: pressure and flow trigger) [92]. In this prospective cross-over study, 18 patients requiring MV were randomized for 10 minutes with the different modes. During NAVA, the peak airway pressure was lower, the respiratory rate was 10 breaths/minute higher than in the pressure group, and patient-ventilator synchronization was improved. However, there were no differences in tidal volume and in oxygen saturation.

To evaluate the effects of the neural trigger on trigger delay, ventilator response time, or work of breathing, Clement and colleagues conducted a study in 23 pediatric patients aged 0 to 24 months with a diagnosis of bronchiolitis presenting respiratory failure requiring MV [33]. The authors compared the neural trigger and the pneumatic trigger using similar NAVA assistance, and observed that the trigger delay, the ventilator response time, and the work of breathing were reduced by the neural trigger.

Finally, all of these studies seem to demonstrate the feasibility of and a potential advantage for NAVA in children compared with the other assisted ventilatory modes. Because patient-ventilator synchrony is improved with NAVA, the children may require lower doses of sedation with this mode of MV [93], which could reduce the time of MV.

\section{Future research}

Clinical studies obtained in critically ill patients confirm many of the expected short-term physiological benefits associated with NAVA, as discussed above.

Particularly, NAVA seems to markedly improve the problems of nonsynchronization between the patient and the ventilator and the problems of risk of overventilation including the risk of ineffective or missed inspiratory efforts due to intrinsic PEEP observed in chronic obstructive pulmonary disease patients, or to a rapid breathing frequency with a very small tidal volume observed in pediatric patients.

In addition, NAVA minimizes the risk of overinflation because the duration and level of pressurization remain under respiratory-center control, and minimizes the risk of diaphragmatic inactivity because the presence of pressure assistance requires the presence of this inspiratory activity.

A preserved respiratory muscle function is pivotal for weaning from MV [44]. By using NAVA, which outperforms the previous modes of MV for adequately assisting the patient's inspiratory effort without inducing patient/ventilator dyssynchrony, a reduction in the duration of MV could be expected. Studies are needed to evaluate the best time to begin the weaning process with NAVA.

The NAVA setting is an important question not yet fully resolved. If clinicians are accustomed to set a PSV level, this is not the case for NAVA. Furthermore, because the breathing pattern is less modified by the NAVA setting than during PSV, it is much less informative for NAVA adjustment. As described above, the literature 
suggests that the adjustment should consider the electromyographic activity of the diaphragm, but this method is not simple. As recently proposed, a direct evaluation of patient comfort and sense of dyspnea for the NAVA setting should be evaluated [23].

Finally, the next research step will be to evaluate NAVA over longer periods, in order to know whether this mode can replace the modes usually used during MV and the weaning period, like PSV. Appreciating the safety, the feasibility and the constraints of this technology will be useful. It is therefore necessary to test, during the total weaning period, the effectiveness of the esophageal probe and to know whether it is regularly necessary to adjust the probe position. One of the most difficult questions to address, however, is in which situations it is not desirable to let the respiratory centers drive the ventilation. Situations of severe metabolic acidosis, of high respiratory drive and of high catecholamine levels may induce situations of extreme hyperventilation, which may be dangerous for the lungs. When sedation and/or paralysis become necessary is therefore an important question to address before widespread use of this mode [94].

\section{Conclusion}

NAVA, which is based on an original physiological concept, adds new knowledge on patient-ventilator interactions during spontaneous breathing, thus helping to unravel the complex mechanisms involved in breathing control during MV. There is compelling evidence that NAVA, as well as the PAV + software, improves patientventilator interactions and increases respiratory variability in comparison with PSV. This advantage holds potential for many applications. The short-term and long-term experience with NAVA, however, remains scant. Further clinical studies are needed to assess the feasibility and safety of NAVA. A key challenge is how to determine the best NAVA settings according to the patient's ventilatory needs and the acceptable level of work of breathing.

\section{Abbreviations}

EAdi, electrical activity of the diaphragm; MV, mechanical ventilation; NAVA, neurally adjusted ventilatory assist; NEXmod, nose to ear lobe to xiphoid process of the sternum distance modified for the EAdi catheter; NIV, noninvasive ventilation; $\mathrm{PaCO}_{2}$, partial pressure of carbon dioxide in arterial blood; PAV, proportional-assist ventilation; Paw, airway pressure; PEEP, positive end-expiratory pressure; PSV, pressure-support ventilation; $V_{T}$, tidal volume.

\section{Competing interests}

SJ received a grant from Maquet Critical Care SA in 2009 and 2010 for clinical research. PJ's research laboratory received grants from Maquet Critical Care SA Drager, Res-Med, Hamilton, for clinical research over the last 5 years. LB's research laboratory received a grant from Maquet Critical Care SA in 2009 and 2010 for clinical research. LB's research laboratory has also received research grants from Drager, Covidien, General Electric and Fisher Paykel over the last 5 years. J-CMR and AM received grants from Drager, Covidien, and General Electric over the last 5 years for their research group. AD's research laboratory received a grant from Maquet Critical Care SA in 2008 and 2009 for clinical research. AD coordinates a multicenter clinical study on NAVA. The remaining authors declare that they have no competing interests.

\section{Author contributions}

NT, J-CMR and LB initiated and wrote the manuscript; all authors contributed to the revision of this. All authors read and approved the final manuscript.

\section{Acknowledgements}

The round-table meeting was initiated and organized solely by the authors. Maquet Critical Care SA provided financial support for travel and accommodation costs, thus allowing the authors to meet for a half-day conference, but had no influence on the content of the manuscript.

\section{Author details}

'INSERM U1075, Caen F-14000, France. 2Université de Caen, Caen F-14000, France. ${ }^{3} \mathrm{CHRU}$ Caen, Service de Réanimation Médicale, Caen F-14000, France. ${ }^{4}$ Adult Intensive Care and Burn Unit, Lausanne University Hospital (CHUV), Rue du Bugnon 46, 1011 Lausanne, Switzerland. ${ }^{5}$ Department of Anaesthesiology and Intensive Care 2, Bordeaux University Hospital, F-33000 Bordeaux, France. ${ }^{6}$ LUNAM Université, Angers, France Université Angers, CHU Angers, Medical ICU, 4 rue Larrey, 49933 Angers, Cedex 09 France. ${ }^{7}$ University Angers, CHU Angers, Réanimation Médicale, 49933 Angers, France. ${ }^{8}$ Centre d'Investigation Clinique - Innovations Technologiques, Services de Physiologie - Explorations Fonctionnelles, Hôpital Raymond Poincaré, AP-HP, E.A. 4497, Université de Versailles - Saint Quentin en Yvelines, 92380 Garches, France. ${ }^{9}$ INSERM U955, 94000 Créteil, France. ${ }^{10}$ Hôpital du Sacré-Coeur de Montréal, 5400 boul. Gouin Ouest Montréal, Québec, H4J 1C5, Canada. "Intensive Care Unit, Clinique Notre Dame de Grâce, Gosselies Hospital, 212 Chaussée de Nivelles, B-6041-Gosselies, Belgium. ${ }^{12}$ Intensive Care Unit, University Hospital St-Luc, 10 avenue Hippocrate, 1200 Brussels, Belgium. ${ }^{13}$ Medical Intensive Care Unit and Respiratory Division, Groupe Hospitalier Pitié-Salpêtrière, Université Pierrer et Marie Curie and INSERM974, Paris, France. ${ }^{14}$ Department of Critical Care Medicine and Anesthesiology (DAR B), Saint Eloi University Hospital and Universite of Montpellier, INSERM U1046, 80 Avenue Augustin Fliche, 34295 Montpellier, France. ${ }^{15}$ Intensive Care Unit, Hospital de Sant Pau C. St Quinti 89, 08041 Barcelona, Spain. ${ }^{16}$ Intensive Care Unit, Geneva University Hospital, School of Medicine, University of Geneva, Rue Gabrielle-Perret-Gentil 4, 1205 Geneva, Switzerland. ${ }^{17}$ Medical Intensive Care Unit, University Hospital, Charles Nicolle, 76000 Rouen, France. ${ }^{18}$ UPRES EA3830, Rouen, France.

Published: 20 June 2012

\section{References}

1. Esteban A, Anzueto A, Alía I, Gordo F, Apezteguía C, Pálizas F, Cide D, Goldwaser R, Soto L, Bugedo G, Rodrigo C, Pimentel J, Raimondi G, Tobin MJ: How is mechanical ventilation employed in the intensive care unit? An international utilization review. Am J Respir Crit Care Med 2000, 161:1450-1458.

2. Esteban A, Ferguson ND, Meade MO, Frutos-Vivar F, Apezteguia C, Brochard L, Raymondos K, Nin N, Hurtado J, Tomicic V, González M, Elizalde J, Nightingale P, Abroug F, Pelosi P, Arabi Y, Moreno R, Jibaja M, D'Empaire G, Sandi F, Matamis D, Montañez AM, Anzueto A; VENTILA Group: Evolution of mechanical ventilation in response to clinical research. Am J Respir Crit Care Med 2008, 177:170-177.

3. Cereda M, Foti G, Marcora B, Gili M, Giacomini M, Sparacino ME, Pesenti A: Pressure support ventilation in patients with acute lung injury. Crit Care Med 2000, 28:1269-1275.

4. Nava S, Bruschi C, Fracchia C, Braschi A, Rubini F: Patient-ventilator interaction and inspiratory effort during pressure support ventilation in patients with different pathologies. Eur Respir J 1997, 10:177-183.

5. Navalesi P, Costa R: New modes of mechanical ventilation: proportional assist ventilation, neurally adjusted ventilatory assist, and fractal ventilation. Curr Opin Crit Care 2003, 9:51-58.

6. Moerer O: Effort-adapted modes of assisted breathing. Curr Opin Crit Care 2012, 18:61-69.

7. Younes M, Puddy A, Roberts D, Light RB, Quesada A, Taylor K, Oppenheimer L, Cramp H: Proportional assist ventilation. Results of an initial clinical trial. Am Rev Respir Dis 1992, 145:121-129.

8. Giannouli E, Webster K, Roberts D, Younes M: Response of ventilatordependent patients to different levels of pressure support and proportional assist. Am J Respir Crit Care Med 1999, 159:1716-1725.

9. Alexopoulou C, Kondili E, Vakouti E, Klimathianaki M, Prinianakis G, Georgopoulos D: Sleep during proportional-assist ventilation with loadadjustable gain factors in critically ill patients. Intensive Care Med 2007, 33:1139-1147. 
10. Ranieri VM, Giuliani R, Mascia L, Grasso S, Petruzzelli V, Puntillo N, Perchiazzi G, Fiore T, Brienza A: Patient-ventilator interaction during acute hypercapnia: pressure-support vs. proportional-assist ventilation. J Appl Physiol 1996, 81:426-436.

11. Bosma K, Ferreyra G, Ambrogio C, Pasero D, Mirabella L, Braghiroli A, Appendini L, Mascia L, Ranieri VM: Patient-ventilator interaction and sleep in mechanically ventilated patients: pressure support versus proportional assist ventilation. Crit Care Med 2007, 35:1048-1054

12. Grasso S, Puntillo F, Mascia L, Ancona G, Fiore T, Bruno F, Slutsky AS, Ranier VM: Compensation for increase in respiratory workload during mechanical ventilation. Pressure-support versus proportional-assist ventilation. Am J Respir Crit Care Med 2000, 161(3 Pt 1):819-826.

13. Younes M, Webster K, Kun J, Roberts D, Masiowski B: A method for measuring passive elastance during proportional assist ventilation. Am J Respir Crit Care Med 2001, 164:50-60.

14. Younes M, Kun J, Masiowski B, Webster K, Roberts D: A method for noninvasive determination of inspiratory resistance during proportional assist ventilation. Am J Respir Crit Care Med 2001, 163:829-839.

15. Kondili E, Prinianakis G, Alexopoulou C, Vakouti E, Klimathianaki M, Georgopoulos D: Respiratory load compensation during mechanical ventilation - proportional assist ventilation with load-adjustable gain factors versus pressure support. Intensive Care Med 2006, 32:692-699.

16. Xirouchaki N, Kondili E, Vaporidi K, Xirouchakis G, Klimathianaki M, Gavriilidis G, Alexandopoulou E, Plataki M, Alexopoulou C, Georgopoulos D: Proportional assist ventilation with load-adjustable gain factors in critically ill patients: comparison with pressure support. Intensive Care Med 2008, 34:2026-2034

17. Costa R, Spinazzola G, Cipriani F, Ferrone G, Festa O, Arcangeli A, Antonelli M, Proietti R, Conti G: A physiologic comparison of proportional assist ventilation with load-adjustable gain factors $(\mathrm{PAV}+$ ) versus pressure support ventilation (PSV). Intensive Care Med 2011, 37:1494-1500.

18. Sinderby C, Navalesi P, Beck J, Skrobik Y, Comtois N, Friberg S, Gottfried SB Lindstrom $L$ : Neural control of mechanical ventilation in respiratory failure. Nat Med 1999, 5:1433-1436.

19. Wu XY, Huang YZ, Yang Y, Liu SQ, Liu HG, Qiu HB: [Effects of neurally adjusted ventilatory assist on patient-ventilator synchrony in patients with acute respiratory distress syndrome]. Zhonghua Jie He He Hu Xi Za Zhi 2009, 32:508-512.

20. Brander L, Leong-Poi H, Beck J, Brunet F, Hutchison SJ, Slutsky AS, Sinderby C: Titration and implementation of neurally adjusted ventilatory assist in critically ill patients. Chest 2009, 135:695-703.

21. Colombo D, Cammarota G, Bergamaschi V, De Lucia M, Corte FD, Navalesi P. Physiologic response to varying levels of pressure support and neurally adjusted ventilatory assist in patients with acute respiratory failure. Intensive Care Med 2008, 34:2010-2018.

22. Spahija J, de Marchie M, Albert M, Bellemare P, Delisle S, Beck J, Sinderby C: Patient-ventilator interaction during pressure support ventilation and neurally adjusted ventilatory assist. Crit Care Med 2010, 38:518-526.

23. Schmidt M, Demoule A, Cracco C, Gharbi A, Fiamma MN, Straus C, Duguet A, Gottfried SB, Similowski T: Neurally adjusted ventilatory assist increases respiratory variability and complexity in acute respiratory failure. Anesthesiology 2010, 112:670-681.

24. Rozé H, Lafrikh A, Perrier V, Germain A, Dewitte A, Gomez F, Janvier G, Ouattara A: Daily titration of neurally adjusted ventilatory assist using the diaphragm electrical activity. Intensive Care Med 2011, 37:1087-1094.

25. Terzi N, Pelieu I, Guittet L, Ramakers M, Seguin A, Daubin C, Charbonneau P, du Cheyron D, Lofaso F: Neurally adjusted ventilatory assist in patients recovering spontaneous breathing after acute respiratory distress syndrome: physiological evaluation. Crit Care Med 2010, 38:1830-1837.

26. Piquilloud L, Vignaux L, Bialais E, Roeseler J, Sottiaux T, Laterre PF, Jolliet P, Tassaux D: Neurally adjusted ventilatory assist improves patient-ventilator interaction. Intensive Care Med 2011, 37:263-271.

27. Coisel Y, Chanques G, Jung B, Constantin JM, Capdevila X, Matecki S, Grasso S, Jaber $S$ : Neurally adjusted ventilatory assist in critically ill postoperative patients: a crossover randomized study. Anesthesiology 2010, 113:925-935.

28. Passath C, Takala J, Tuchscherer D, Jakob SM, Sinderby C, Brander L: Physiologic response to changing positive end-expiratory pressure during neurally adjusted ventilatory assist in sedated, critically ill adults. Chest 2010, 138:578-587.

29. Beck J, Reilly M, Grasselli G, Mirabella L, Slutsky AS, Dunn MS, Sinderby C: Patient-ventilator interaction during neurally adjusted ventilatory assist in low birth weight infants. Pediatr Res 2009, 65:663-668.
30. Bengtsson JA, Edberg KE: Neurally adjusted ventilatory assist in children: an observational study. Pediatr Crit Care Med 2010, 11:253-257.

31. Breatnach C, Conlon NP, Stack M, Healy M, O'Hare BP: A prospective crossover comparison of neurally adjusted ventilatory assist and pressuresupport ventilation in a pediatric and neonatal intensive care unit population. Pediatr Crit Care Med 2010, 11:7-11.

32. Cammarota G, Olivieri C, Costa R, Vaschetto R, Colombo D, Turucz E, Longhini F, Della Corte F, Conti G, Navalesi P: Noninvasive ventilation through a helmet in postextubation hypoxemic patients: physiologic comparison between neurally adjusted ventilatory assist and pressure support ventilation. Intensive Care Med 2011, 37:1943-1950.

33. Clement KC, Thurman TL, Holt SJ, Heulitt MJ: Neurally triggered breaths reduce trigger delay and improve ventilator response times in ventilated infants with bronchiolitis. Intensive Care Med 2011, 37:1826-1832

34. Thille AW, Rodriguez P, Cabello B, Lellouche F, Brochard L: Patient-ventilator asynchrony during assisted mechanical ventilation. Intensive Care Med 2006, 32:1515-1522.

35. Tobin MJ, Jubran A, Laghi F: Patient-ventilator interaction. Am J Respir Crit Care Med 2001, 163:1059-1063.

36. Parthasarathy S, Jubran A, Tobin MJ: Cycling of inspiratory and expiratory muscle groups with the ventilator in airflow limitation. Am J Respir Crit Care Med 1998, 158(5 Pt 1):1471-1478.

37. Beck J, Tucci M, Emeriaud G, Lacroix J, Sinderby C: Prolonged neural expiratory time induced by mechanical ventilation in infants. Pediatr Res 2004, 55:747-754.

38. de Wit M, Pedram S, Best AM, Epstein SK: Observational study of patientventilator asynchrony and relationship to sedation level. J Crit Care 2009, 24:74-80.

39. Dreyfuss D, Saumon G: Ventilator-induced lung injury: lessons from experimental studies. Am J Respir Crit Care Med 1998, 157:294-323.

40. Ricard JD, Dreyfuss D, Saumon G: Ventilator-induced lung injury. Eur Respir J Supp/ 2003, 42:2s-9s.

41. The Acute Respiratory Distress Syndrome Network: Ventilation with lower tidal volumes as compared with traditional tidal volumes for acute lung injury and the acute respiratory distress syndrome. N Engl J Med 2000, 342:1301-1308.

42. Levine S, Nguyen T, Taylor N, Friscia ME, Budak MT, Rothenberg P, Zhu J, Sachdeva R, Sonnad S, Kaiser LR, Rubinstein NA, Powers SK, Shrager JB: Rapid disuse atrophy of diaphragm fibers in mechanically ventilated humans. NEngl J Med 2008, 358:1327-1335.

43. Sieck GC, Mantilla CB: Effect of mechanical ventilation on the diaphragm. NEngl J Med 2008, 358:1392-1394.

44. Jaber S, Petrof BJ, Jung B, Chanques G, Berthet JP, Rabuel C, Bouyabrine H, Courouble P, Koechlin-Ramonatxo C, Sebbane M, Similowski T, Scheuermann V, Mebazaa A, Capdevila X, Mornet D, Mercier J, Lacampagne A, Philips A, Matecki S: Rapidly progressive diaphragmatic weakness and injury during mechanical ventilation in humans. Am J Respir Crit Care Med 2011, 183:364-371.

45. Anzueto A, Peters JI, Tobin MJ, de los Santos R, Seidenfeld JJ, Moore G, Cox WJ, Coalson JJ: Effects of prolonged controlled mechanical ventilation on diaphragmatic function in healthy adult baboons. Crit Care Med 1997, 25:1187-1190.

46. Sassoon CS: Ventilator-associated diaphragmatic dysfunction. Am J Respir Crit Care Med 2002, 166:1017-1018.

47. Sassoon CS, Caiozzo VJ, Manka A, Sieck GC: Altered diaphragm contractile properties with controlled mechanical ventilation. J Appl Physiol 2002, 92:2585-2595

48. Sassoon CS, Zhu E, Caiozzo VJ: Assist-control mechanical ventilation attenuates ventilator-induced diaphragmatic dysfunction. Am J Respir Crit Care Med 2004, 170:626-632

49. Thille AW, Cabello B, Galia F, Lyazidi A, Brochard L: Reduction of patientventilator asynchrony by reducing tidal volume during pressure-support ventilation. Intensive Care Med 2008, 34:1477-1486.

50. Pinto Da Costa N, Di Marco F, Lyazidi A, Carteaux G, Sarni M, Brochard L: Effect of pressure support on end-expiratory lung volume and lung diffusion for carbon monoxide. Crit Care Med 2011, 39:2283-2289.

51. Barwing J, Ambold M, Linden N, Quintel M, Moerer O: Evaluation of the catheter positioning for neurally adjusted ventilatory assist. Intensive Care Med 2009, 35:1809-1814.

52. Barwing J, Pedroni C, Quintel M, Moerer O: Influence of body position, PEEP and intra-abdominal pressure on the catheter positioning for neurally adjusted ventilatory assist. Intensive Care Med 2011, 37:2041-2045. 
53. Parthasarathy S, Jubran A, Tobin MJ: Assessment of neural inspiratory time in ventilator-supported patients. Am J Respir Crit Care Med 2000, 162(2 Pt 1):546-552

54. Calderini E, Confalonieri M, Puccio PG, Francavilla N, Stella L, Gregoretti C: Patient-ventilator asynchrony during noninvasive ventilation: the role of expiratory trigger. Intensive Care Med 1999, 25:662-667.

55. Vignaux L, Tassaux D, Carteaux G, Roeseler J, Piquilloud L, Brochard L, Jolliet P: Performance of noninvasive ventilation algorithms on ICU ventilators during pressure support: a clinical study. Intensive Care Med 2010, 36:2053-2059.

56. Leung $\mathrm{P}$, Jubran A, Tobin MJ: Comparison of assisted ventilator modes on triggering, patient effort, and dyspnea. Am J Respir Crit Care Med 1997, 155:1940-1948.

57. Tassaux D, Gainnier M, Battisti A, Jolliet P: Impact of expiratory trigger setting on delayed cycling and inspiratory muscle workload. Am J Respir Crit Care Med 2005, 172:1283-1289.

58. American Thoracic Society/European Respiratory Society: ATS/ERS Statement on respiratory muscle testing. Am J Respir Crit Care Med 2002, 166:528-547.

59. Moerer O, Beck J, Brander L, Costa R, Quintel M, Slutsky AS, Brunet F, Sinderby $C$ : Subject-ventilator synchrony during neural versus pneumatically triggered non-invasive helmet ventilation. Intensive Care Med 2008, 34:1615-1623.

60. Thille AW, Lyazidi A, Richard JC, Galia F, Brochard L: A bench study of intensive-care-unit ventilators: new versus old and turbine-based versus compressed gas-based ventilators. Intensive Care Med 2009, 35:1368-1376.

61. Allo JC, Beck JC, Brander L, Brunet F, Slutsky AS, Sinderby CA: Influence of neurally adjusted ventilatory assist and positive end-expiratory pressure on breathing pattern in rabbits with acute lung injury. Crit Care Med 2006 34:2997-3004

62. Brander L, Sinderby C, Lecomte F, Leong-Poi H, Bell D, Beck J, Tsoporis JN, Vaschetto R, Schultz MJ, Parker TG, Villar J, Zhang H, Slutsky AS: Neurally adjusted ventilatory assist decreases ventilator-induced lung injury and non-pulmonary organ dysfunction in rabbits with acute lung injury. Intensive Care Med 2009, 35:1979-1989.

63. Sinderby C, Beck J, Spahija J, de Marchie M, Lacroix J, Navalesi P, Slutsky AS: Inspiratory muscle unloading by neurally adjusted ventilatory assist during maximal inspiratory efforts in healthy subjects. Chest 2007, 131:711-717.

64. Guz A: Hering and Breuer revisited in humans: an invasive study before the days of ethics committees. Am J Respir Crit Care Med 2001 164:1110-1111.

65. Patroniti N, Bellani G, Saccavino E, Zanella A, Grasselli G, Isgro S, Milan M, Foti $G$, Pesenti A: Respiratory pattern during neurally adjusted ventilatory assist in acute respiratory failure patients. Intensive Care Med 2012, 38:230-239.

66. Putensen C, Rasanen J, Lopez FA, Downs JB: Effect of interfacing between spontaneous breathing and mechanical cycles on the ventilationperfusion distribution in canine lung injury. Anesthesiology 1994, 81:921-930.

67. Gama de Abreu M, Spieth PM, Pelosi P, Carvalho AR, Walter C, Schreiber-Ferstl A, Aikele P, Neykova B, Hubler M, Koch T: Noisy pressure support ventilation: a pilot study on a new assisted ventilation mode in experimental lung injury. Crit Care Med 2008, 36:818-827.

68. Brack T, Jubran A, Tobin MJ: Effect of elastic loading on variational activity of breathing. Am J Respir Crit Care Med 1997, 155:1341-1348.

69. Brack T, Jubran A, Tobin MJ: Effect of resistive loading on variational activity of breathing. Am J Respir Crit Care Med 1998, 157(6 Pt 1):1756-1763.

70. Brack T, Jubran A, Tobin MJ: Dyspnea and decreased variability of breathing in patients with restrictive lung disease. Am J Respir Crit Care Med 2002, 165:1260-1264

71. Sammon MP, Bruce EN: Vagal afferent activity increases dynamical dimension of respiration in rats. J Appl Physiol 1991, 70:1748-1762.

72. Fiamma MN, Straus C, Thibault S, Wysocki M, Baconnier P, Similowski T: Effects of hypercapnia and hypocapnia on ventilatory variability and the chaotic dynamics of ventilatory flow in humans. Am J Physiol Regul Integr Comp Physio/ 2007, 292:R1985-R1993.

73. Wysocki M, Fiamma MN, Straus C, Poon CS, Similowski T: Chaotic dynamics of resting ventilatory flow in humans assessed through noise titration. Respir Physiol Neurobiol 2006, 153:54-65.

74. Schurmann T, Grassberger P: Entropy estimation of symbol sequences Chaos 1996, 6:414-427.
75. Briggs K: An improved method for estimating Liapunov exponents of chaotic time series. Phys Lett A 1990, 151:27-32.

76. Lofaso F, Isabey D, Lorino H, Harf A, Scheid P: Respiratory response to positive and negative inspiratory pressure in humans. Respir Physio/ 1992, 89:75-88.

77. Scheid P, Lofaso F, Isabey D, Harf A: Respiratory response to inhaled CO during positive inspiratory pressure in humans. J Appl Physio/ 1994, 77:876-882.

78. Karagiannidis C, Lubnow M, Philipp A, Riegger GA, Schmid C, Pfeifer M, Mueller T: Autoregulation of ventilation with neurally adjusted ventilatory assist on extracorporeal lung support. Intensive Care Med 2010, 36:2038-2044

79. Lecomte F, Brander L, Jalde F, Beck J, Qui H, Elie C, Slutsky AS, Brunet F, Sinderby C: Physiological response to increasing levels of neurally adjusted ventilatory assist (NAVA). Respir Physio/ Neurobio/ 2009, 166:117-124.

80. Barwing J, Linden N, Ambold M, Quintel M, Moerer O: Neurally adjusted ventilatory assist vs. pressure support ventilation in critically ill patients: an observational study. Acta Anaesthesio/ Scand 2011, 55:1261-1271.

81. Ververidis D, Van Gils M, Passath C, Takala J, Brander L: Identification of adequate neurally adjusted ventilatory assist (NAVA) during systematic increases in the NAVA level. IEEE Trans Biomed Eng 2011, 58:2598-2606.

82. Sinderby C, Spahija J, Beck J, Kaminski D, Yan S, Comtois N, Sliwinski P. Diaphragm activation during exercise in chronic obstructive pulmonary disease. Am J Respir Crit Care Med 2001, 163:1637-1641.

83. Vignaux L, Vargas F, Roeseler J, Tassaux D, Thille AW, Kossowsky MP, Brochard $L$, Jolliet $P$ : Patient-ventilator asynchrony during non-invasive ventilation for acute respiratory failure: a multicenter study. Intensive Care Med 2009, 35:840-846.

84. Terzi N, Orlikowski D, Aegerter P, Lejaille M, Ruquet M, Zalcman G, Fermanian C, Raphael JC, Lofaso F: Breathing-swallowing interaction in neuromuscular patients: a physiological evaluation. Am J Respir Crit Care Med 2007, 175:269-276.

85. Terzi N, Prigent H, Lejaille M, Falaize L, Annane D, Orlikowski D, Lofaso F: Impact of tracheostomy on swallowing performance in Duchenne muscular dystrophy. Neuromuscul Disord 2010, 20:493-498.

86. Orlikowski D, Terzi N, Blumen M, Sharshar T, Raphael JC, Annane D, Lofaso F: Tongue weakness is associated with respiratory failure in patients with severe Guillain-Barre syndrome. Acta Neurol Scand 2009, 119:364-370.

87. Roche Campo F, Drouot X, Thille AW, Galia F, Cabello B, d'Ortho MP, Brochard $L$ : Poor sleep quality is associated with late noninvasive ventilation failure in patients with acute hypercapnic respiratory failure. Crit Care Med 2010, 38:477-485.

88. Fanfulla F, Delmastro M, Berardinelli A, Lupo ND, Nava S: Effects of different ventilator settings on sleep and inspiratory effort in patients with neuromuscular disease. Am J Respir Crit Care Med 2005, 172:619-624.

89. Delisle $S$, Ouellet $P$, Bellemare $P$, Tetrault JP, Arsenault P. Sleep quality in mechanically ventilated patients: comparison between NAVA and PSV modes. Ann Intensive Care 2011, 1:42.

90. Fauroux B, Leroux K, Desmarais G, Isabey D, Clement A, Lofaso F, Louis B: Performance of ventilators for noninvasive positive-pressure ventilation in children. Eur Respir J 2008, 31:1300-1307.

91. Beck J, Campoccia F, Allo JC, Brander L, Brunet F, Slutsky AS, Sinderby C: Improved synchrony and respiratory unloading by neurally adjusted ventilatory assist (NAVA) in lung-injured rabbits. Pediatr Res 2007, 61:289-294.

92. Alander M, Peltoniemi O, Pokka T, Kontiokari T: Comparison of pressure-, flow-, and NAVA-triggering in pediatric and neonatal ventilatory care. Pediatr Pulmonol 2012, 47:76-83.

93. Rhoney DH, Murry KR: National survey of the use of sedating drugs, neuromuscular blocking agents, and reversal agents in the intensive care unit. J Intensive Care Med 2003, 18:139-145.

94. Papazian L, Forel JM, Gacouin A, Penot-Ragon C, Perrin G, Loundou A, Jaber S, Arnal JM, Perez D, Seghboyan JM, Constantin JM, Courant P, Lefrant JY, Guérin C, Prat G, Morange S, Roch A; ACURASYS Study Investigators: Neuromuscular blockers in early acute respiratory distress syndrome. N Engl J Med 2010, 363:1107-1116.

doi:10.1186/cc11297

Cite this article as: Terzi N, et al.: Clinical review: Update on neurally

adjusted ventilatory assist - report of a round-table conference. Critical Care 2012, 16:225. 